\title{
New insights into cytomixis: specific cellular features and prevalence in higher plants
}

\author{
Sergey R. Mursalimov $\cdot$ Yuri V. Sidorchuk • \\ Elena V. Deineko
}

Received: 30 April 2013 / Accepted: 5 June 2013 / Published online: 18 June 2013

(C) Springer-Verlag Berlin Heidelberg 2013

\begin{abstract}
The phenomenon of intercellular migration of nuclei in plant tissues (cytomixis) was discovered over a century ago, which has been followed by numerous attempts to clarify the essence of this process as well as to determine its causes and consequences. Most attention of researchers has been paid to cytomixis in microsporogenesis, since the transfer of part of genetic material between microsporocytes may influence the ploidy level of the produced pollen and, presumably, have an evolutionary significance. This review compiles the data on cytological pattern of cytomixis and proposes a scheme as to how cytomictic channels are formed and function in angiosperms. The prevalence of cytomixis in different plant taxa is analyzed using the published data. The causes, mechanisms, and consequences of the nuclear migration between cells in plant tissues are discussed.
\end{abstract}

Keywords Microsporogenesis - Cytomictic channels . Intercellular communication $\cdot$ Cell wall

\section{Introduction}

Cytomixis is migration of the nuclei from one plant cell to another through intercellular channels of a special type (cytomictic channels), differing from plasmodesmata in

Electronic supplementary material The online version of this article (doi:10.1007/s00425-013-1914-0) contains supplementary material, which is available to authorized users.

S. R. Mursalimov $(\bowtie) \cdot$ Y. V. Sidorchuk · E. V. Deineko Laboratory of Plant Bioengineering, Institute of Cytology and Genetics, Siberian Branch, Russian Academy of Sciences, pr. Lavrentieva 10, Novosibirsk 630090, Russian Federation e-mail: mursalimovsr@gmail.com their structure and size. This unique phenomenon was discovered over a century ago (Arnoldy 1900; Gates 1911) and was for a long time regarded as an artifact resulting from the damages of plant material during its fixation and processing (Takats 1959). However, Baquar and Husain (1969) experimentally refuted the belief that cytomixis was a nonspecific response to a direct mechanical or chemical impact on the plant cells. Moreover, it has been demonstrated that any direct damaging impacts on the cell completely arrest cytomixis (Liu et al. 2007). It has been also repeatedly shown that intact plants display a high rate of cytomixis (Bahl and Tyagi 1988; Bellucci et al. 2003; Sidorchuk et al. 2007a), and video monitoring of cytomixis in living cells finally resolved the question on a supposed artificial nature of this process (Zhang et al. 1990).

Intercellular migration of nuclei has been observed in manifold types of plant tissues, for example, apical meristem cells of woody plants (Guzicka and Wozny 2005) and vegetative tissues of the anther (Wang et al. 2004). However, cytomixis is most frequently detectable in plant meiosis, especially in microsporocytes (Lattoo et al. 2006; Kumar et al. 2010) and never in megasporocytes.

A comprehensive analysis of cytomixis is of a paramount importance for both the insight into intercellular communication in plant tissues and assessment of the evolutionary consequences caused by migration of genetic material between the cells producing pollen. Despite that there are yet no direct experimental evidences for an evolutionary significance of cytomixis, ever more researchers recently are inclined to favor the hypothesis about involvement of cytomixis in the evolutionary processes due to production of unreduced gametes or gametes with varying chromosome numbers (Falistocco et al. 1995; Ghaffari 2006; Lattoo et al. 2006; Negron-Ortiz 2007; Singhal et al. 2011). 
In this review, we attempt to assemble the new and most important experimental data on cytomixis as well as to analyze how prevalent is this phenomenon among higher plants.

\section{Cytological picture of cytomixis}

The specific cytological features of cytomixis manifest themselves in different plant species in a similar manner and are most comprehensively described in the microsporogenesis of angiosperms based on light microscopy examination (Sidorchuk et al. 2007a; Kumar et al. 2010; Guan et al. 2012). Most frequently, cytomixis is observable in the microsporocytes in the prophase of the first meiotic division (Bellucci et al. 2003); however, this phenomenon can be also detected at the subsequent meiotic stages, including the tetrad stage (Ressayre et al. 2003; Kumar et al. 2010). It should be emphasized that the plant species differ in the maximal rate of cytomixis at different stages of microsporogenesis. In particular, the highest rate of cytomictic nuclear migrations in the tobacco and sweet pea is observed during meiotic prophase I (Seijo 1996; Sidorchuk et al. 2007a) and in the rape and wild turnip, during telophase II and tetrad stage (De Souza and Pagliarini 1997). In the microsporogenesis of the cowpea and species of the genus Festuca, cytomixis is detectable at all the stages of microsporogenesis starting from meiotic prophase I and through the stage of microspore tetrads (Sen and Bhattacharya 1988; Sheidai and Bagheri-Shabestarei 2007).

Not only the stage of maximum cytomixis manifestation depends on the studied plant species but also the rate of cytomixis. It has been shown that, for example, cytomixis in the rape anthers is observable only in $0.06 \%$ of the microsporocytes (De Souza and Pagliarini 1997) versus up to $96 \%$ in the almond (Soodan and Wafai 1987). It has been also demonstrated that the number of cells involved in cytomixis varies in a wide range not only between individual plants of the same species, but also between different flowers of the same plant (Soodan and Wafai 1987; Peng et al. 2003). As a rule, the rate of cytomixis increases in response to stress factors acting on a plant, such as mutagens, increased temperatures, changes in the ploidy level, hybridization, and so on (Saraswathy Amma et al. 1990; Ghaffari 2006; Sidorchuk et al. 2007a; Kravets 2011).

A typical picture of cytomixis in the tobacco microsporocytes is shown in Fig. 1 (Sidorchuk et al. 2007a); in this plant, the maximal number of the nuclei migrating between cells is observed in the pachytene. Cytomixis commences with elongation of the donor cell nucleus toward the site of a cytomictic channel (CC) followed by its transfer to the recipient cell (Fig. 1b, c). At the entrance to $\mathrm{CC}$, the nuclear chromatin considerably condenses; however, its normal structure is restored in the recipient cell (Fig. 1d) and most frequently one or several micronuclei are formed during division of the migrating nucleus (Fig. 1e). The nucleus with its overall content can concurrently migrate between microsporocytes through one or several (up to ten) CCs (Fig. 1b, c, f, g). As a rule, two cells are involved in cytomixis, one acting as a donor and the other as a recipient (Fig. 1b, c). However, it can be frequently observed that a cell exchanges its chromatin concurrently with several adjacent cells (Fig. 1f). Chains of cells united by successively migrating chromatin also may be rather frequently seen (Fig. 1g).

Quite interesting patterns have been observed when studying cytomixis in microsporogenesis of the poppy (Papaver somniferum), carrying B chromosomes in its karyotype (Patra et al. 1988). The authors noticed that the $\mathrm{B}$ chromosomes during cytomixis were first to migrate to the recipient cell followed by the A chromosome set. They referred this phenomenon as the B-chromosome-pioneered cytomixis and assumed that the heterochromatin blocks of B chromosomes played an important role in this process. In addition, cells with different number of chromosomes were observed among the microsporocytes, and pollen displayed size variation but still had a high fertility (Patra et al. 1988). An analogous pattern of the B-chromosomepioneered cytomixis was observed in microsporogenesis of Panax pseudo-ginseng (Patra 1986). This suggests that the association of $\mathrm{B}$ chromosomes and cytomixis requires a close attention.

Of special interest is video monitoring of intercellular migration of the nuclei between living cells of the wheat endosperm performed by Zhang et al. (1990). They have shown that the transition of a nucleus from one cell to another requires about $30 \mathrm{~min}$. Even a reversible nuclear migration-where the nucleus of a cell passed to a neighboring cell, remained there for several minutes, and returned home through the same channels-was observed in several cases (Zhang et al. 1990).

The pattern of nuclear migration observed at the level of light microscopy has been confirmed by the data obtained with the help of electron microscopy. At an ultrastructural level, researchers have observed migrations of nuclei through single or multiple $\mathrm{CCs}$, chromatin condensation in $\mathrm{CCs}$, restoration of its structure in the recipient cell, formation of micronuclei, and formation of the cell chains connected via migrating nuclei (Heslop-Harrison 1966; Whelan et al. 1974; Feijo and Pais 1989; Wang et al. 2002; Mursalimov and Deineko 2011). In addition, an ultrastructural examination allowed for discovery of the specific features of cytomixis, undetectable at the level of light microscopy. In particular, it has been shown that no visual damages of nuclear envelope and chromatin are seen during cytomixis and that the nucleolus can change its shape 

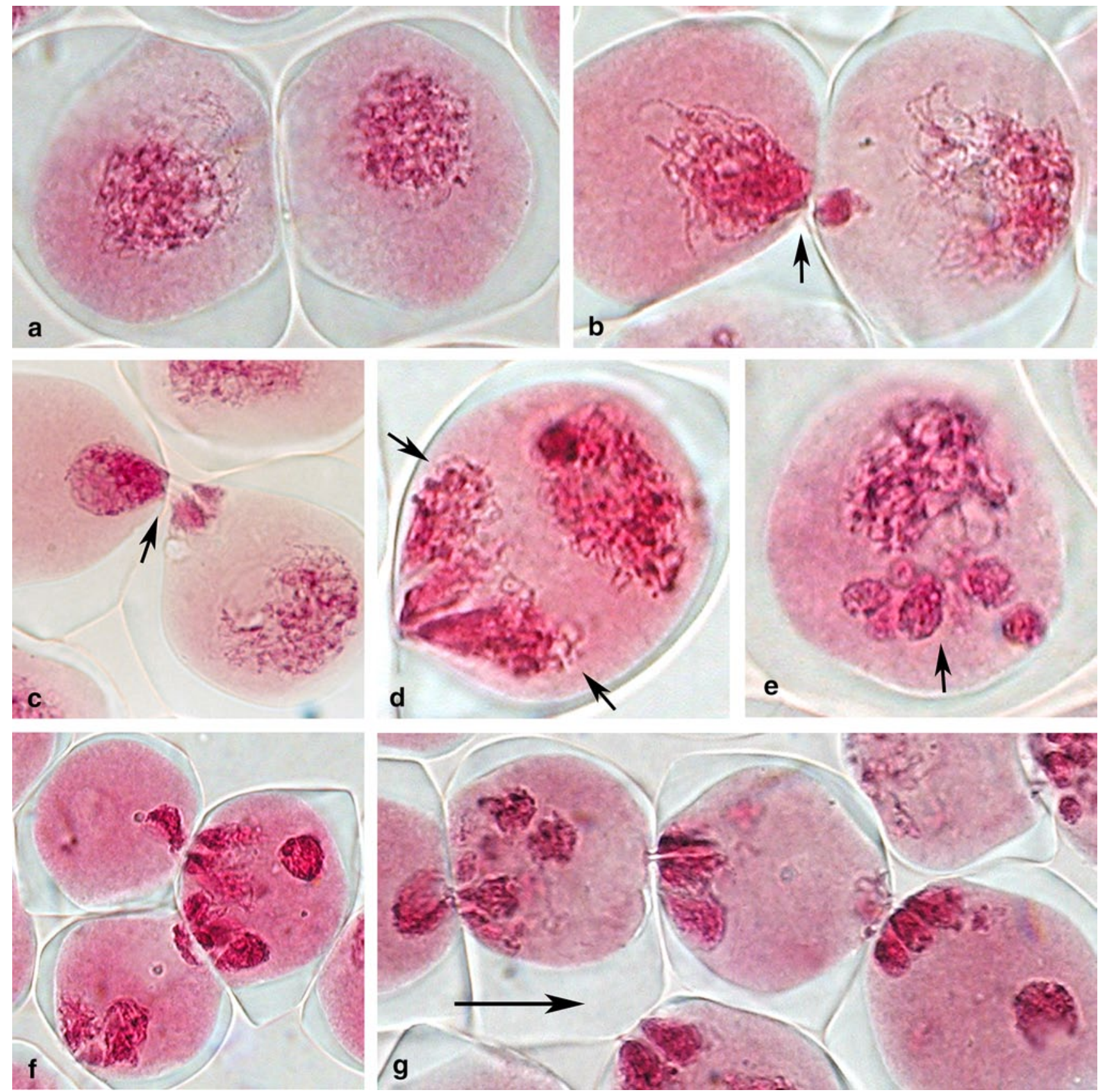

Fig. 1 Cytological picture of cytomixis in the tobacco microsporogenesis at the pachytene in meiotic prophase I (Sidorchuk et al. 2007a). a Microsporocytes without cytomixis. b Migration of chromatin through one cytomictic channel (arrow). c Migration of chromatin through several cytomictic channels (arrow). d Recovery

and divide into parts to pass through CCs (Wang et al. 2002; Mursalimov and Deineko 2011).

An original phenomenon, discovered with the help of electron microscopy, is formation of nuclear bridges, that is, the structures directly connecting the nuclei of adjacent cells through a CC (Mursalimov and Deineko 2011). The nuclear bridge (Fig. 2) is formed during cytomixis, when of chromatin structure in a recipient cell (arrows). e Formation of micronuclei after cytomixis (arrow). f One cell is a recipient of chromatin for two neighboring cells. $\mathrm{g}$ A chain of cells united by migrating chromatin (arrow indicates direction of chromatin migration)

a nuclear envelope projection of one nucleus $\left(\mathrm{n}_{2}\right)$ spans the cell wall through a CC and fuses with the nucleus of the adjacent cell $\left(\mathrm{n}_{1}\right)$, thereby forming a direct contact, a bridge surrounded by the nuclear envelope and containing the chromatin inside.

So far, the nuclear bridge formation in cytomixis has been observed only in the tobacco (Mursalimov and 
Fig. 2 Cytomixis with nuclear bridge formation in the pachytene in tobacco microsporocytes (Mursalimov and Deineko 2011). Cytomictic channels (arrows) and a nuclear bridge (white arrow); 1-3 numbers of cells, $n_{1}-n_{3}$ the nuclei of the corresponding cells, $c w$ cell wall. Bar represents $2 \mu \mathrm{m}$. Inset shows an upscaled nuclear bridge; integrity of the nuclear envelope in the nuclear bridge (arrows) is shown; ch chromatin. Bar represents $500 \mathrm{~nm}$

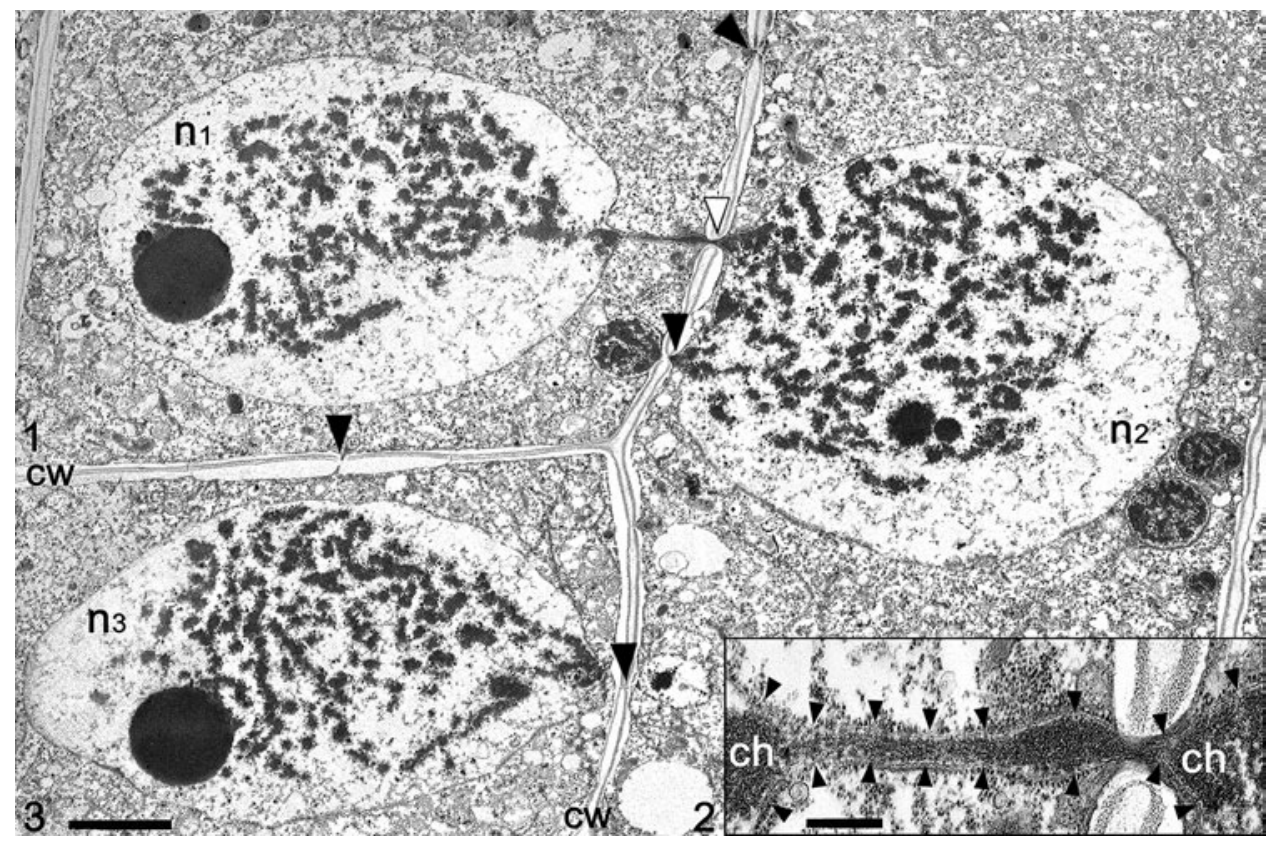

Deineko 2011); however, it is quite possible that such structures are formed in microsporogenesis of other plant species as well. Because of a very small size and instability, these bridges can be detected only by electron microscopy examination specially focused on the search for the structures in question.

Despite that we regard the term "cytomixis" only as the migration of nuclei, the possibility of migration of the cytoplasm and cell organelles, such as mitochondria and plastids, through CCs has been also demonstrated by the example of microsporocytes (Feijo and Pais 1989; Wang et al. 2006; Mursalimov et al. 2010). The cytomictic migration of plastids attracts a special attention, since it has been repeatedly demonstrated that the plastids carrying selective traits can migrate between cells of vegetative tissues at the zone of transplant fusion (Stegemann and Bock 2009; Thyssen et al. 2012). Presumably, CCs also play a key role in this case; however, the mechanisms of their formation in somatic tissues require a separate study.

\section{Cellular mechanisms}

It looks rather improbable that migration of the nucleus, the size of which manifold exceeds that of CCs, may be a mere passive flow between cells. The fact that cytomixis is arrested by $\mathrm{KCN}$ solution or a decrease in temperature (Zhang et al. 1985) suggests that this phenomenon is an active energy-dependent process. Most likely, cytoskeletal elements are also involved in this process.

Usually, the nucleus occupies a fixed position in the cell; however, there are known cases where nuclei do migrate to fulfill certain tasks. For example, the root growth is accompanied by migration of the nuclei from epidermal cells into the middle part of root hair (Chytilova et al. 1999) or nuclei of the filamentous fungi migrate along the growing hypha to uniformly spread over its space (Suelmann et al. 1997). The nuclear migration in these cases is provided for by the interaction of cytoskeleton and motor proteins (Suelmann et al. 1997; Fischer 1999; Liu et al. 2003). It is reasonable to assume that the cytomictic nuclear migration is implemented in a similar manner. Several experimental data also favor this hypothesis. For example, as in vivo monitoring of cytomixis in the wheat endosperm has demonstrated that a migrating nucleus constantly contacts a large number of filamentous structures attached to the nuclear envelope (Zhang et al. 1990). An analogous pattern was observed in the lily microsporocytes at an ultrastructural level: microtubule-like elements were evident inside the $\mathrm{CC}$ and were connected with migrating organelles (Wang et al. 2002). Nonetheless, immunofluorescence assay of the tubulin cytoskeleton in meiosis of the tobacco plants with a high rate of cytomixis failed to find any specific features in its dynamics or organization that would allow them to be associated with the intercellular nuclear migration (Sidorchuk et al. 2007b). Thus, it is logical to assume that the actin cytoskeleton rather than the tubulin part of the plant cell cytoskeleton plays the key role in the cytomictic migration of the nuclei. This assumption is supported by the fact that cytochalasin B stops the migration of cell content through CCs, since this toxin particularly prevents the growth of actin microfilaments (Zhang et al. 1985). However, the involvement of microfilaments in cytomixis has not been analyzed in detail, most likely due to the difficulties in visualizing the actin cytoskeleton in plant microsporogenesis. 


\section{Cytomictic channels}

CCs are a special class of intercellular contacts in plant tissues. Their emergence in the cell wall allows the nuclei and other organelles to migrate from one cell to another. Unlike plasmodesmata, CCs have no internal structure, such as desmotubules and, as a rule, CCs are considerably larger than plasmodesmata; the $\mathrm{CC}$ diameter ranges from 50 to 3,500 nm (Heslop-Harrison 1966; Wang et al. 1998; Wang et al. 2002; Mursalimov et al. 2010). In addition, CCs may occupy over $25 \%$ of the cell surface (HeslopHarrison 1966). Scanning electron microscopy has demonstrated that CCs may either cluster at the sites of cell contacts or uniformly spread over the entire cell surface; note that this is a species-specific characteristic (Whelan et al. 1974).

The literature and our own data suggest the following scheme for the $\mathrm{CC}$ formation and function in the angiosperm microsporogenesis (Fig. 3). Primary CCs are formed in early meiotic prophase I (leptotene-zygotene), when the cell wall is represented by a middle lamella with a thin cellulose layer and is spanned with plasmodesmata (Fig. 3a). Note that the hydrolytic enzymes released by the endoplasmic reticulum and Golgi apparatus are involved in the CC formation (Wang et al. 1998; Yu et al. 2004). At this stage, CCs can be formed, on the one hand, based on plasmodesmata via enlargement of a single plasmodesma
(Fig. 3b, channel 1) or fusion of several plasmodesmata (Fig. 3b, channel 3) and, on the other, de novo (Fig. 3b, channel 2) on the cell wall regions lacking any plasmodesmata (Wang et al. 1998; Yu et al. 2004; Mursalimov et al. 2010).

Once the primary CCs are formed, migration of nuclei through these channels begins (Fig. 3b). Usually the nuclei migrate to a recipient cell concurrently through several CCs (Fig. 3b). Most frequently, the result of such migration is formation of micronuclei (Fig. 3c, asterisks) or, in some cases, nuclear bridges (Fig. 3c, NB).

During meiotic prophase I, the pectin-cellulose cell wall is gradually replaced by the callose wall (Fig. 3d), which covers cells until the tetrad stage; in this process, the primary CCs disappear (Wang et al. 2002; Mursalimov and Deineko 2012). However, it has been shown that secondary CCs can be formed in the callose wall and the specific organelles-spherosome-like vesicles, containing the enzyme callase-are involved in this process (Mursalimov et al. 2010; 2013). These organelles release their content into the cell wall, thereby locally destructing callose and forming the secondary CCs, which provide for cytomixis during all meiotic stages, including the late stages (Fig. 3d). Presumably, the processes of primary and secondary CC formation are species-specific and may considerably differ from the above-described pattern in various plant species.
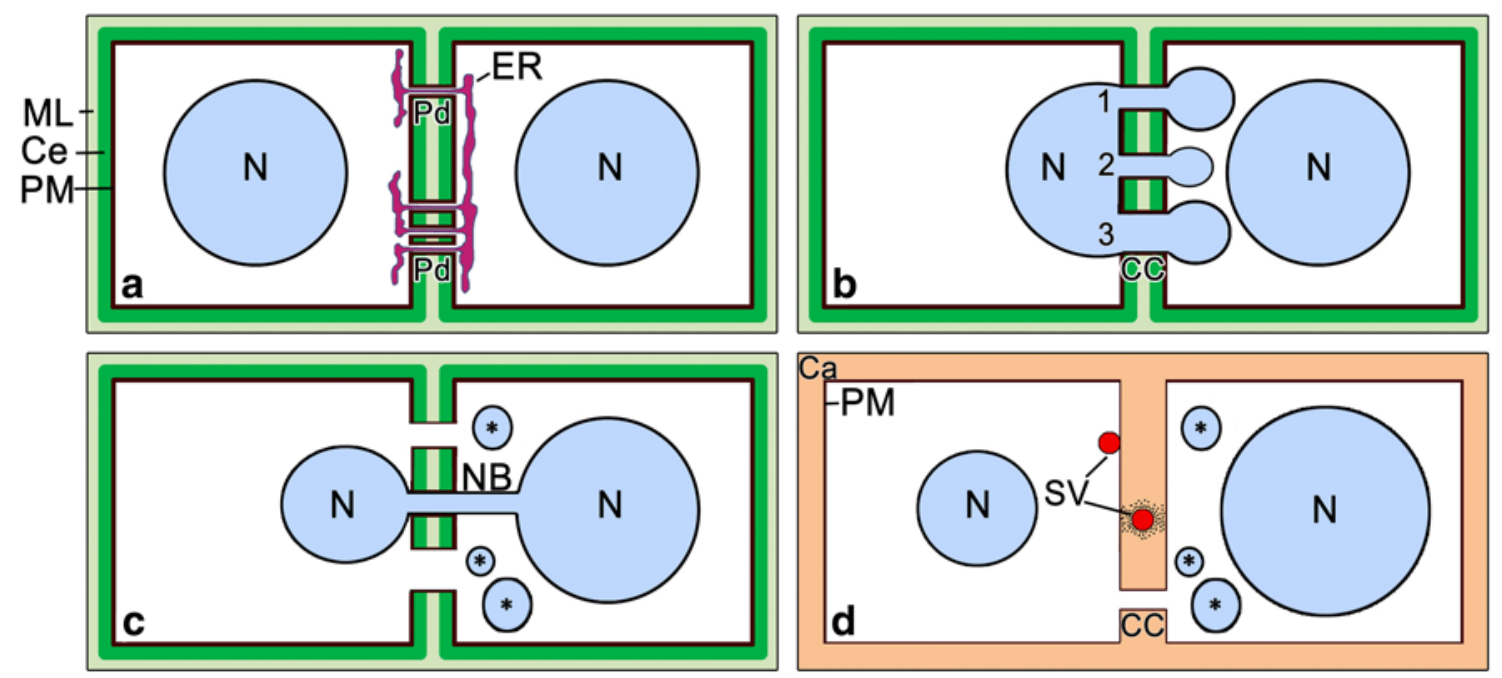

Fig. 3 Scheme of formation and function of cytomictic channels in the angiosperm microsporogenesis (nuclei migrate through $\mathrm{CCs}$ from left to right). a Microsporocytes entering meiosis; cells are surrounded by the primary cell wall and connected by plasmodesmata. b, c Microsporocytes at zygotene-pachytene; cells are connected with CCs either formed of plasmodesmata or independently of them. Nuclei migrate through channels; micronuclei and, in some cases, nuclear bridges are formed in the recipient cell as a result of cyto- mixis. d Microsporocytes at late pachytene; the primary cell wall is replaced by callose; the primary $\mathrm{CCs}$ are closed; and the secondary CCs are formed with the help of spherosome-like vesicles. $M L$ middle lamella, $C$ e cellulose, $P M$ plasma membrane, $E R$ endoplasmic reticulum, $P d$ plasmodesma, $C C$ cytomictic channel, $N$ nucleus, $N B$ nuclear bridge, $C a$ callose, $S V$ spherosome-like vesicles, and asterisks micronucleus 
Prevalence in higher plants

To estimate to what degree the phenomenon of cytomixis is significant in the plant kingdom, it is necessary to understand how wide it is represented in different taxonomic units. In the literature, we have succeeded in finding descriptions of cytomixis in the microsporogenesis of over 400 plant species belonging to 84 families (Supplemental Table S1). Among the angiosperms, the family Poaceae contains the highest number of such species (82) in the monocots and the family Fabaceae (48) in the dicots.

The absolute majority of the instances of cytomixis have been described in the microsporogenesis of angiosperms. It is rather curious that we have not found in the literature any information about cytomixis in the microsporogenesis of gymnosperms, although intercellular migration of nuclei is observed in somatic tissues of these plants (Guzicka and Wozny 2005) and the very phenomenon of cytomixis was first discovered in the gymnosperm megagametophyte (Arnoldy 1900).

The events of nuclear migration between cells have been also observed in other divisions of higher plants, for example, among the Isoetaceae quillworts (He et al. 2004; Heng-Chang et al. 2007). Formation of CCs but without migration of nuclei through them has been observed in the microsporocytes of horsetails and ferns (Lehmann et al. 1984; Gabarayeva et al. 2011). In this case, it is possible that cytomixis just has not been detected and will be successfully observed by a more detailed analysis of microsporogenesis in these plants.

Note that intercellular nuclear migration has been found in the plants represented by manifold life forms, for example, grasses (starwort; Jeelani et al. 2011) and trees (hevea; Saraswathy Amma et al. 1990). Analysis of the published data has shown no correlation between the rate of cytomixis and species-specific number of chromosomes. Cytomixis has been observed with different frequencies in the microsporogenesis of the species with both a small chromosome set (Plantago ovata Forsk, $2 n=8$; Singh 1986) and a large chromosome set (Consolea rubescens, $2 n=88$; Negron-Ortiz 2007). Moreover, cytomixis is rather frequently observed within the same species in the forms with different ploidy levels, for example, diploids, triploids, or tetraploids (Jeelani et al. 2011; Kumar and Singhal 2011; Lavia et al. 2011; Guan et al. 2012).

Note that the papers describing cytomixis in somatic tissues as well as in the microsporogenesis of hybrid plant forms have not been included into Table S1. However, even with this restriction, we have succeeded in finding the data on intercellular migration of nuclei in hundreds of species (Supplemental Table S1). This fact suggests that cytomixis can be regarded as a normal phenomenon in microsporogenesis, characteristic of the majority of (or even all) angiosperm species.

\section{Causes and consequences}

Since the discovery of cytomixis, the questions on the biological role of CCs and consequences of nuclear migration through them are still to be answered. According to one of the hypotheses, the $\mathrm{CC}$ emergence is determined by the need in the contact between developing microsporocytes for synchronization of divisions and exchange with nutrients (Milyaeva 1965; Heslop-Harrison 1966; Mursalimov et al. 2010). It is reasonable to regard CCs as the ways for exchange with nutrients and informational molecules. Formation of a thick callose wall during microsporogenesis entails reduction of the apoplastic transport between the cells and creates the need in increase in the symplastic one, which may explain $\mathrm{CC}$ emergence, the more so since analogous intercellular channels are also observable in other organisms. For example, the cytoplasmic channels directly connecting individual cells have been discovered in the development of animal male gametes (Ventelä et al. 2003). Similar structures (ring channels) are formed between Drosophila oocytes and nursing cells (Bohrmann and Biber 1994). The so-called nanotubes, which are direct cytoplasmic channels between cells allowing whole organelles to migrate through them, have been observed between mammalian cells (Gerdes et al. 2007; Zani and Edelman 2010). The role of such channels is reduced to intercellular transport of nutrients and regulatory factors as well as synchronization of cell development (Bohrmann and Biber 1994; Ventelä et al. 2003). An analogy to the channels between animal cells suggests that CCs in plant tissues fulfill the same functions.

However, ever more increasing volume of new intriguing data suggests that the role of CCs is not confined to a mere exchange with nutrients and informational molecules between plant cells. Presumably, their fundamental role is in the transfer of part of genetic material from one cell to another via cytomixis resulting in an increase in genetic diversity of the produced pollen or an adjusting and balancing in unbalanced genomes (Falistocco et al. 1995; Zhou 2003; Ghaffari 2006; Lattoo et al. 2006; Negron-Ortiz 2007; Singhal and Kumar 2008; Song and Li 2009; Singhal et al. 2011).

It is known that polyploidization is one of the major pathways in plant evolution (Ramsey and Schemske 1998). The most important mechanism leading to polyploid plants is formation of the gametes with a diploid chromosome number (Bretagnolle and Thompson 1995). Diploid gametes can be produced in several ways, and cytomixis might well be one of them (Falistocco et al. 1995; Ghaffari 2006; Lattoo et al. 2006). On the other hand, cytomixis may be 
involved in elimination of the "surplus" DNA by discharging part of the chromatin from the nucleus to the cytoplasm of another cell, thereby providing for either stabilization of a polyploid genome or return from a polyploid to a diploid state (Cheng et al. 1987; Baptista-Giacomelli and Pagliarini 2000; Zhou 2003; Kalinka et al. 2010).

An evolutionary significance of cytomixis has been assumed long ago (Kamra 1960); however, the first data that confirm this hypothesis appeared only in the last decade. First and foremost, this is a frequent detection of fertile diploid and polyploid pollen in the plants displaying a high rate of cytomixis in their microsporogenesis (Falistocco et al. 1995; Zhou 2003; Ghaffari 2006; Lattoo et al. 2006; Negron-Ortiz 2007; Singhal and Kumar 2008; Song and Li 2009; Singhal et al. 2011).

The issue on preservation of cell viability and functional activity after involvement in cytomixis is the decisive question for the insight into the consequences of this phenomenon. If the microsporocytes involved in migration of nuclei continue their development and form microspores and eventually pollen, this allows for consideration of the possibility of change in the karyotype of these cells with the help of cytomixis. However, if these cells degrade as a result of partial loss of chromatin or acquisition of its additional portion, then cytomixis is unable to directly influence pollen formation. Theoretically, the migrated chromatin in a recipient cell can be either eliminated or integrated with the recipient nucleus via a direct fusion of two nuclei or in the metaphase via incorporation of migrated chromosomes into metaphase plate. However, any data available so far can convincingly prove neither elimination of migrated chromatin nor its integration with the nucleus of a recipient cell.

\section{Conclusions}

Despite a long-term history of the research into cytomixis, the key question associated with this processwhat is the fate of the migrating chromatin-still remains unanswered. The cytological picture of this phenomenon as well as its response to the impacts of various external and internal factors and prevalence in various types of plant cells and different plant taxa has been studied in considerable detail. However, the result of such transfer of genetic material between cells is still vague. Currently, the opinions of researchers on this issue vary and only indirect data are available as confirmations. We believe that the nearest future will bring novel data obtained by state-of-the-art molecular and cytological methods that will help answer the question on the fate of migrating chromatin and the biological role of cytomixis.
Acknowledgments The work was supported by the Russian Foundation for Basic Research (Grant No. 11-04-01192-a) and "OPTEC" LLC.

\section{References}

Arnoldy W (1900) Beiträge zur Morphologie der Gymnospermen. IV. Was sind die "Keimbläschen" oder "Hofmeisters-Körperchen" in der Eizelle der Abietineen? Flora 87:194-204

Bahl JR, Tyagi BR (1988) Cytomixis in pollen mother cells of Papaver dubium L. Cytologia 53:771-775

Baptista-Giacomelli FR, Pagliarini MS, Almeida JL (2000) Elimination of micronuclei from microspores in a Brazilian oat (Avena sativa $\mathrm{L}$.) variety. Genet Mol Biol 23:681-684

Baquar SR, Husain SA (1969) Cytoplasmic channels and chromatin migration in the meiocytes of Arnebia hispidissima (Sieb.) DC. Ann Bot 33:821-837

Bellucci M, Roscini C, Mariani A (2003) Cytomixis in pollen mother cells of Medicago sativa L. J Hered 94:512-516

Bohrmann J, Biber K (1994) Cytoskeleton-dependent transport of cytoplasmic particles in previtellogenic to mid-vitellogenic ovarian follicles of Drosophila: time-lapse analysis using videoenhanced contrast microscopy. J Cell Sci 107:849-858

Bretagnolle F, Thompson JD (1995) Tansley review no. 78. Gametes with the somatic chromosome number: mechanisms of their formation and role in the evolution of atotpolyploid plants. New Phytol 129:1-22

Cheng KC, Quiglan Y, Yongren Z (1987) The relationship between cytomixis, chromosome mutation and karyotype evolution in Lily. Caryologia 40:243-259

Chytilova E, Macas J, Galbraith DW (1999) Green fluorescent protein targeted to the nucleus, a transgenic phenotype useful for studies in plant biology. Ann Bot 83:645-654

De Souza AM, Pagliarini MS (1997) Cytomixis in Brassica napus var. oleifera and Brassica campestris var. oleifera (Brassicaceae). Cytologia 62:25-29

Falistocco E, Tosti N, Falcinelli M (1995) Cytomixis in pollen mother cells of diploid Dactylis, one of the origins of $2 \mathrm{n}$ gametes. J Hered 86:448-453

Feijo JA, Pais MS (1989) Cytomixis in meiosis during the microsporogenesis of Ophrys lutea: an ultrastructural study. Caryologia 42:37-48

Fischer R (1999) Nuclear movement in filamentous fungi. FEMS Microbiol Rev 23:39-68

Gabarayeva NI, Grigorjeva VV, Marquez G (2011) Ultrastructure and development during meiosis and the tetrad period of sporogenesis in the leptosporangiate fern Alsophila setosa (Cyatheaceae) compared with corresponding stages in Psilotum nudum (Psilotaceae). Grana 50:235-261

Gates RR (1911) Pollen formation in Oenothera gigas. Ann Bot 25:909-940

Gerdes HH, Bukoreshtliev NV, Barroso JF (2007) Tunneling nanotubes: a new route for the exchange of components between animal cells. FEBS Lett 581:2194-2201

Ghaffari SM (2006) Occurrence of diploid and polyploidy microspores in Sorghum bicolor (Poaceae) is the result of cytomixis. Afr J Biotech 5:1450-1453

Guan JZ, Wang JJ, Cheng ZH et al (2012) Cytomixis and meiotic abnormalities during microsporogenesis are responsible for male sterility and chromosome variations in Houttuynia cordata. Genet Mol Res 11:121-130

Guzicka M, Wozny A (2005) Cytomixis in shoot apex of Norway spruce [Picea abies (L.) Karst.]. Trees 18:722-724 
He Z, Wang H, Li J et al (2004) Chromosome behavior during meiosis and development of spore mother cells in the Chinese quillwort Isoetes sinensis T. C. Palmer (Isoetaceae). Amer Fern J 94:183-195

Heng-Chang W, Li J-Q, He Z-C (2007) Irregular meiotic behavior in Isoetes sinensis (Isoetaceae), a rare and endangered fern in China. Caryologia 60:358-363

Heslop-Harrison J (1966) Cytoplasm connections between angiosperm meiocytes. Ann Bot 30:221-230

Jeelani SM, Rani S, Kumar S et al (2011) Meiotic studies in some members of Caryophyllaceae Juss. from the Western Himalayas. Acta Biologica Cracoviensia Ser Bot 53:86-95

Kalinka A, Achrem M, Rogalska SM (2010) Cytomixis-like chromosomes/chromatin elimination from pollen mother cells (PMCs) in wheat-rye allopolyploids. Nucleus 53:69-83

Kamra OP (1960) Chromatin extrusion and cytomixis in pollen mother cells of Hordeum. Hereditas 46:592-600

Kravets E (2011) The role of cell selection for pollen grain fertility after treatment of barley sprouts (Hordeum distichum L.) with UV-B irradiation. Acta Biol Slov 54:31-41

Kumar P, Singhal VK (2011) Male meiosis, morphometric analysis and distribution pattern of $2 \times$ and $4 \times$ cytotypes of Ranunculus hirtellus Royle, 1834 (Ranunculaceae) from the cold regions of Northwest Himalayas (India). Comp Cytogen 5:143-161

Kumar P, Singhal VK, Kaur D, Kaur S (2010) Cytomixis and associated meiotic abnormalities affecting pollen fertility in Clematis orientalis. Biol Plant 54:181-184

Lattoo SK, Khan S, Bamotra S, Dhar AK (2006) Cytomixis impairs meiosis and influences reproductive success in Chlorophytum comosum (Thunb) Jacq. - an additional strategy and possible implications. J Biosci 31:629-637

Lavia GI, Ortiz AM, Robledo G et al (2011) Origin of triploid Arachis pintoi (Leguminosae) by autopolyploidy evidenced by FISH and meiotic behaviour. Ann Bot 108:103-111

Lehmann H, Neidhart HV, Schlenkermann G (1984) Ultrastructural investigations on sporogenesis in Equisetum tluviatile. Protoplasma 123:38-47

Liu H, Guo GQ, He Y, Zheng GC (2003) Nuclear migration: endless efforts toward unraveling its molecular apparatus. Chin Sci Bull 48:615-619

Liu H, Guo G-Q, He Y-K et al (2007) Visualization on intercellular movement of chromatin in intact living anthers of transgenic tobacco expressing histone 2B-CFP Fusion Protein. Caryologia 60:1-20

Milyaeva EL (1965) To the question about cytomixis during microsporogenesis. Bull Bot Gard Acad Sci USSR (in Russian) 59:53-59

Mursalimov SR, Deineko EV (2011) An ultrastructural study of cytomixis in tobacco pollen mother cells. Protoplasma 248:717-724

Mursalimov SR, Deineko EV (2012) An ultrastructural study of microsporogenesis in tobacco line SR1. Biologia 67:369-376

Mursalimov SR, Baiborodin SI, Sidorchuk YV et al (2010) Characteristics of the cytomictic channel formation in Nicotiana tabacum L. pollen mother cells. Cytol Genet 44:14-18

Mursalimov S, Sidorchuk Y, Deineko E (2013) The role of spherosome-like vesicles in formation of cytomictic channels between tobacco microsporocytes. Biol Plant 57:291-297

Negron-Ortiz V (2007) Chromosome numbers, nuclear DNA content, and polyploidy in Consolea (Cactaceae), an endemic cactus of the Caribbean Islands. Am J Bot 94:1360-1370

Patra NK (1986) Identification of a new kind of cytomixis in Himalayan panax (Panax pseudo-ginseng subsp. himalaicus Hara). Cytologia 51:301-308

Patra NK, Srivastava HK, Chauhan SP (1988) B chromosomes in spontaneous and induced intercellular chromosome migration of Papaver somniferum. Indian J Genet 48:31-42
Peng ZS, Yang J, Zheng GC (2003) Cytomixis in pollen mother cells of new synthetic hexaploid amphidiploid (Aegilops tauschii $\times$ Triticum turgidum). Cytologia 68:335-340

Ramsey J, Schemske DW (1998) Pathways, mechanisms, and rates of polyploid formation in flowering plants. Ann Rev Ecol Syst 29:467-501

Ressayre A, Mignot A, Siljak-Yakovlev S, Raquin C (2003) Postmeiotic cytokinesis and pollen aperture number determination in eudicots: effect of the cleavage wall number. Protoplasma 221:257-268

Saraswathy Amma CK, Namboodiri AN, Panikkar AON, Sethuraj MR (1990) Radiation induced male sterility in Hevea brasiliensis (Willd. ex Adr. De Juss.) Muell. Arg Cytologia 55:547-551

Seijo G (1996) Spontaneous cytomixis in the microsporogenesis of sweet pea Lathyrus odoratus L. (Leguminosae). Cytologia 61:189-195

Sen O, Bhattacharya S (1988) Cytomixis in Vigna glaberscens TTK1 (Wild). Cytologia 53:437-440

Sheidai M, Bagheri-Shabestarei E-S (2007) Cytomixis and unreduced pollen formation in some Festuca L. species of Iran. Caryologia 60:364-371

Sidorchuk YV, Deineko EV, Shumny VK (2007a) Peculiarities of cytomixis in pollen mother cells of transgenic tobacco plants (Nicotiana tabacum L.) with mutant phenotype. Cell Tissue Biol 1:570-576

Sidorchuk YV, Deineko EV, Shumny VK (2007b) Role of microtubular cytoskeleton and callose walls in the manifestation of cytomixis in pollen mother cells of tobacco Nicotiana tabacum L. Cell Tissue Biol 1:577-581

Singh RK (1986) Cytomixis in Plantago ovata. Cur Sci 55:658-659

Singhal VK, Kumar P (2008) Impact of cytomixis on meiosis, pollen viability and pollen size in wild populations of Himalayan poppy (Meconopsis aculeata Royle). J Biosci 33:371-380

Singhal VK, Rana PK, Kumar P, Kaur D (2011) Persistent occurrence of meiotic abnormalities in a new hexaploid cytotype of Thalictrum foetidum from Indian cold deserts. Biologia 66: 458-464

Song ZQ, Li XF (2009) Cytomixis in pollen mother cells of Salvia miltiorrhiza. Caryologia 62:213-219

Soodan AS, Wafai BA (1987) Spontaneous occurrence of cytomixis during microsporogenesis in almond (Prunus amygdalus Batsch) and peach (Prunus persica Batsch). Cytologia 52:361-364

Stegemann S, Bock R (2009) Exchange of genetic material between cells in plant tissue grafts. Science 324:649-651

Suelmann R, Sievers N, Fischer R (1997) Nuclear traffic in fungal hyphae: in vivo study of nuclear migration and positioning in Aspergillus nidulans. Mol Microbiol 25:757-769

Takats ST (1959) Chromatin extrusion and DNA transfer during microsporogenesis. Chromosoma 10:430-453

Thyssen G, Svab Z, Maliga P (2012) Cell-to-cell movement of plastids in plants. Proc Natl Acad Sci USA 109:2439-2443

Ventelä S, Toppari J, Parvinen M (2003) Intercellular organelle traffic through cytoplasmic bridges in early spermatids of the rat: mechanisms of haploid gene product sharing. Mol Biol Cell 14:2768-2780

Wang XY, Guo GQ, Nie XW, Zheng GC (1998) Cytochemical localization of cellulase activity in pollen mother cells of David lily during meiotic prophase I and its relation to secondary formation of plasmodesmata. Protoplasma 204:128-138

Wang XY, Nie XW, Guo GQ et al (2002) Ultrastructural characterization of the cytoplasmic channel formation between pollen mother cells of David lily. Caryologia 55:161-169

Wang XY, Yu CH, Li X et al (2004) Ultrastructural aspects and possible origin of cytoplasmic channels providing intercellular connection in vegetative tissues of anthers. Russ J Plant Physiol 51:110-120 
Wang CY, Li X, Wu QF, Wang X (2006) Cytoplasmic channels and their association with plastids in male meiocytes of tobacco, onion and lily. Cell Biol Int 30:406-411

Whelan EDP, Haggis GH, Ford EJ (1974) Scanning electron microscopy of the callose wall and intermeiocyte connections in angiosperms. Can J Bot 52:1215-1218

Yu CH, Guo GQ, Nie XW, Zheng GC (2004) Cytochemical localization of pectinase activity in pollen mother cells of tobacco during meiotic prophase I and its relation to the formation of secondary plasmodesmata and cytoplasmic channels. Acta Bot Sinica 46:1443-1453
Zani BG, Edelman ER (2010) Cellular bridges: routes for intercellular communication and cell migration. Commun Integr Biol 3:215-220

Zhang WC, Yan WM, Lou CH (1985) Mechanism of intercellular movement of protoplasm in wheat nucellus. Sci China 28:1175-1183

Zhang WC, Yan WM, Lou CH (1990) Intercellular movement of protoplasm in vivo in developing endosperm of wheat caryopses. Protoplasma 153:193-203

Zhou SQ (2003) Viewing the difference between the diploid and the polyploid in the light of the upland cotton aneuploid. Hereditas 138:65-72 